\title{
Comment on "Nutrient reference values for bioactives: new approaches needed? A conference report" (European Journal of Nutrition, April 2013, Volume 52, Issue 1 Supplement, pp 1-9)
}

\author{
Paula R. Trumbo
}

Published online: 2 June 2013

(c) Springer-Verlag (outside the USA) 2013

I have read this article with much interest and would like to provide some clarification. The abstract of this article notes that the US Food and Drug Administration (FDA) sets a labeling value for dietary fiber based on the Institute of Medicine (IOM) Adequate Intake (AI). In 1993, FDA established a Daily Value for dietary fiber ( $25 \mathrm{~g}$ ) based on a report from the Life Sciences Research Office (LSRO) that was published in 1987 [1]. Although the IOM set an AI for dietary fiber in 2002 [2], the current Daily Value for dietary fiber continues to be based on the 1987 LSRO report.

\section{References}

1. Life Sciences Research Office, Federation of American Societies for Experimental Biology (1987) Physiological effects and health consequences of dietary fiber. Bethesda, MD

2. IOM (2002) Dietary reference intakes for energy, carbohydrate, fiber, fat, fatty acids, cholesterol, protein, and amino acids. National Academies Press, Washington, DC

P. R. Trumbo $(\square)$

Nutrition Programs, Office of Nutrition, Labeling and Dietary

Supplements, Center for Food Safety and Applied Nutrition,

U.S. Food and Drug Administration, College Park, MD, USA

e-mail: Paula.Trumbo@fda.hhs.gov 